\title{
Cryptosporidium spp. in dogs and cats in Poland
}

\author{
Agnieszka Piekara-Stępińska ${ }^{1, A-D, F} \oplus$, Jolanta Piekarska ${ }^{1, A, C, E-F \oplus}$, Michał Gorczykowski ${ }^{1, C} \oplus$ \\ 1 Department of Internal Medicine and Clinic of Diseases of Horses, Dogs and Cats, Division of Parasitology, Faculty of \\ Veterinary Medicine, Wrocław University of Environmental and Life Sciences, Poland \\ A - Research concept and design, B - Collection and/or assembly of data, C - Data analysis and interpretation, \\ $D$ - Writing the article, E - Critical revision of the article, $F$ - Final approval of article
}

Piekara-Stępińska A, Piekarska J, Gorczykowski M. Cryptosporidium spp. in dogs and cats from Poland. Ann Agric Environ Med. 2021; 28(2): 345-347. doi: 10.26444/aaem/120467

\section{Abstract}

Introduction. Cryptosporidium spp. are common protozoan parasites of animals and humans. Due to their zoonotic potential it is important to know their species and prevalence in dogs and cats.

Objective. The aim of the study was to determine the occurrence and molecular characteristics of Cryptosporidium spp. in dogs and cats in Poland.

Materials and method. A total of 365 faecal samples (264 dogs and 101 cats) collected from animals living in Poland were analyzed using the Ziehl-Neelsen staining method and genus-specific PCR assay to amplify the Cryptosporidium 18S rRNA gene.

Results. Cryptosporidium were found in 11 out of the 365 examined stool samples (3\%). PCR analysis identified Cryptosporidium in 9 out of 264 canine stool samples (3.4\%) and 2 out of 101 feline specimens (2\%). DNA sequencing confirmed the presence of $C$. canis and C. parvum in dogs and C. felis in cats.

Conclusion. This is the first molecular characterization of Cryptosporidium spp. infection in dogs and cats in Poland.

\section{Key words}

Cryptosporidium spp., nested PCR, Protozoa, Ziehl-Neelsen method, zoonosis, dogs, cats

\section{INTRODUCTION}

Cryptosporidium is a small $(4-6 \mu \mathrm{m})$, widespread, coccidian parasite affecting the epithelium of the digestive and respiratory tracts in mammals, including humans, reptiles, amphibians and birds [1,2]. Cryptosporidium genus contains over 30 so far recognized species and numerous genotypes [3]. Cats may be infected with C. felis, C. muris, C. ryanae and C. parvum and dogs with C. canis, C. parvum, C. ubiquitum and C. andersoni $[4,5,6]$. Cryptosporidiosis in humans is usually caused by C. hominis, C. meleagridis, C. parvum, and also C. felis and C. canis [7]. Dogs and cats, as intimate companion animals, can be sources of human infections. Prevalence of Cryptosporidium spp. ranges from $0.2 \%-$ $5.9 \%$ in European dogs and from 1.7\% - 8.8\% in European cats $[8,9,10,11]$. In Poland, there are only regional data of Cryptosporidium prevalence in dogs and cats $[12,13]$. Moreover, the genetic diversity of Cryptosporidium spp. in dogs in Poland remains unrecognized.

\section{OBJECTIVE}

The aim of the study was to determine the occurrence and molecular characteristics of Cryptosporidium spp. in dogs and cats in Poland considering their potential to be reservoirs for human cryptosporidiosis.

\footnotetext{
Address for correspondence: Agnieszka Piekara-Stępińska, Department of Internal Medicine and Clinic of Diseases of Horses, Dogs and Cats, Division of Parasitology, Faculty of Veterinary Medicine, Wrocław University of Environmental and Life Sciences, Poland

E-mail: agnieszka.piekara@upwr.edu.pl

Received: 12.02.2020; accepted: 09.04.2020; first published: 29.04.2020
}

\section{MATERIALS AND METHOD}

Between October 2016 - June 2019, 365 fresh faecal samples (264 dogs and 101 cats) were obtained from individual, randomly chosen dogs and cats living in different regions of Poland. Samples were collected from 9 of the 16 Polish provinces (Pomerania, Greater Poland, Opole, Silesia, Lesser Poland, Lower Silesia, Łódź, Holy Cross and Subcarpathia). Animals were grouped based on the age (under one year old, between 1-8-years-old and over 8 years old) and faeces condition (formed, diarrheic). Microscopic diagnosis of Cryptosporidium was performed and 2 smears were made from each faecal sample to detect oocysts. The smears were stained with the Ziehl-Neelsen method and examined under 1,000x magnification with immersion oil. The oocysts were identified based on their size, morphology and colour. DNA was isolated from each faecal sample using Genomic Mini AX Stool (A\&A Biotechnology, Poland), as per the manufacturer's instruction. The DNA samples were stored at $-80^{\circ} \mathrm{C}$ until further use. To identify Cryptosporidium spp. in the stool samples, fragments covering $18 \mathrm{~S}$ rDNA gene were amplified by nested PCR. First, amplification of the 763 bp region was carried out, and next, for secondary PCR, the $587 \mathrm{bp}$ fragment was amplified using $1 \mu \mathrm{l}$ of the first PCR product. Primers, mixture composition and PCR conditions have been described by Ryan et al. [14]. The secondary PCR products were examined electrophoretically in $2 \%$ agarose gels and visualized after staining with Midori Green Advance DNA stain (Genetics). Microscopic examination, DNA isolation and amplification was performed in the Division of Parasitology at the Wrocław University of Environmental and Life Sciences.

PCR products sequencing was performed by Genomed (Poland) in both directions. Identity of the obtained sequences was checked by a blast search (https://blast.ncbi. nlm.nih.gov/Blast.cgi). Copromicroscopic analyses were 
performed using the flotation technique with a sodium nitrate solution (density $1.2 \mathrm{~g} / \mathrm{mL}$ ) to evaluate the presence or absence of cysts, oocysts and helminth eggs. Confidence intervals $(\mathrm{CI})$ at the level of $95 \%(\mathrm{p}=0.05)$ was calculated according to the Wilson method. The Chi-square test $(\chi 2)$ with Yates correction implemented in the STATISTICA ver. 12.0 software package was used to compare the differences in Cryptosporidium infection rates among the investigated groups. Differences were considered significant at $\mathrm{p} \leq 0.05$.

\section{RESULTS AND DISCUSSION}

Cryptosporidium spp. were identified by nested PCR in 9 out of 264 canine stool samples (3.4\%) and 2 out of 101 feline specimens (2\%). The oocysts of Cryptosporidium spp. were detected microscopically in 7 (2.7\%) canine and 1 (1\%) feline stool samples. This frequency was significantly lower than that described for Poland by Gundłach $(27.4 \%$ in dogs and $33.3 \%$ in cats) and Bajer $(12.5 \%$ in sled dogs) $[12,13]$. The results obtained may reflect an improvement in the living conditions of companion animals in Poland, but may be also due to the use of different diagnostic methods. The commercial Cryptosporidium coproantigen ELISA used by Gundłach might yield false positive results [15]. Frequency of Cryptosporidium spp. in dogs from Poland presented in the current study equaled that in other European countries, such as Spain $(4.1 \%-5.5 \%)$, Greece $(5.9 \%)$, France $(2.6 \%)$, United Kingdom (4.6\%), and the Czech Republic (0.6-3.2\%) $[6,9,11,16,17]$. A significantly lower prevalence in Europe was reported for dogs in Italy (0.2\%) [8]. The incidence of Cryptosporidium spp. in cats showed in the presented study (2.3\%) was comparable to that in Austria (1.7\%) [10]. A higher frequency in cats was reported for Spain (8.8\%) and Greece $(6.8 \%)[9,11]$. In the current study, no statistically significant differences were observed related to animal age. Cryptosporidium spp. frequency was similar in diarrheic and non-diarrheic dogs, but in cats the parasite was only in diarrheic ones. The occurrence of other gastrointestinal parasites may influence faecal consistency. Three out of 9 Cryptosporidium-positive dogs were infected with other parasites (Giardia duodenalis, Ancylostomatidae and Cystoisospora spp.). One of 2 Cryptosporidium-positive cats that suffered from diarrhea were concurrently infected with Toxocara cati (Tab. 1). Mixed infections with Cryptosporidium and other protozoan parasites (G. duodenalis and Cystoisospora canis especially) do not seem to be rare and have been previously described [18]. Sequences obtained by genotyping were compared with sequences deposited in GenBank base and 3 cases of $C$. canis and 2 cases of $C$. parvum in dogs were detected (Accession Nos. of reference sequences with the highest similarity to obtained sequences: MK886593.1, KY711523.1 and JX886768.1). In cats, 1 out of 2 positive secondary PCR products was sequenced and $C$. felis identified (KM977642.1). The sequences showed high similarity ( $\geq 99 \%)$ to sequences deposited in the GenBank. C. canis, previously restricted only to dogs, is currently considered as a potentially zoonotic species occurring in human patients $[19,20]$. C. parvum is considered to be a zoonotic species, rarely found in dogs. [3, 6, 21, 22]. C. felis, as one of the most frequently found species in cats, was also occasionally detected in humans, suggesting the possibility of transmission between humans and cats [4, 7, 23, 24]. Similar to other studies performed worldwide, the nested PCR method used in the current study proved to be more sensitive in the detection of Cryptosporidium, compared with the traditional Ziehl-Neelsen staining $[25,26]$ (Tab. 1).

\section{CONCLUSION}

This is the first molecular characterization of Cryptosporidium spp. infection in dogs and cats in Poland. The research showed a low frequency of Cryptosporidium in these animals. The presence of C. canis, C. parvum and C. felis in canine and feline population in Poland suggests that companion animals could be potential reservoirs for human infections of these pathogens.

Table 1. Occurrence of Cryptosporidium spp. in dogs and cats related to clinical symptoms

\begin{tabular}{|c|c|c|c|c|c|c|c|}
\hline \multirow{2}{*}{$\begin{array}{l}\text { Animal species } \\
\text { (n) }\end{array}$} & \multirow{2}{*}{$\begin{array}{l}\text { Clinical symptoms } \\
\text { (n) }\end{array}$} & \multirow{2}{*}{$\begin{array}{l}\text { No. of positive } \\
\text { animals }\end{array}$} & \multirow{2}{*}{$\begin{array}{l}\text { Infection frequencies } \\
\qquad\left(\mathrm{Cl}^{*}\right)\end{array}$} & \multirow{2}{*}{ Age of animals } & \multicolumn{2}{|c|}{ Methods of detection } & \multirow{2}{*}{$\begin{array}{l}\text { Other parasites } \\
\text { (Flotation method) }\end{array}$} \\
\hline & & & & & Cryptosporidium spp. (PCR) & Ziehl-Neelsen & \\
\hline \multirow{8}{*}{$\begin{array}{l}\text { Dog } \\
(264)\end{array}$} & \multirow{3}{*}{$\begin{array}{l}\text { Asymptomatic } \\
\text { (117) }\end{array}$} & \multirow{3}{*}{3} & \multirow{3}{*}{$\begin{array}{c}2.6 \% \\
(0.9-7.3)\end{array}$} & 2 months & C. canis MK886593.1 & positive & - \\
\hline & & & & 6 months & C. parvum JX886768.1 & positive & Cystoisospora spp. \\
\hline & & & & 9 months & C. spp. & positive & - \\
\hline & \multirow{5}{*}{ Diarrhea (147) } & \multirow{5}{*}{6} & \multirow{5}{*}{$\begin{array}{c}4.1 \% \\
(1.9-8.6)\end{array}$} & 2 months & C. canis MK886593.1 & negative & Giardia duodenalis \\
\hline & & & & 5 months & C. spp & positive & $\begin{array}{c}\text { Uncinaria } \\
\text { stenocephala }\end{array}$ \\
\hline & & & & 6 months & C. canis MK886593.1 & positive & - \\
\hline & & & & 8 years & C. spp & positive & - \\
\hline & & & & 10 years & C. parvum KY711523.1 & positive & - \\
\hline \multirow{3}{*}{$\begin{array}{l}\text { Cat } \\
(101)\end{array}$} & Asymptomatic (57) & 0 & $0.0 \%(0-6.3)$ & - & - & - & - \\
\hline & \multirow{2}{*}{ Diarrhea (44) } & \multirow{2}{*}{2} & \multirow{2}{*}{$\begin{array}{c}4.6 \% \\
(1.3-15.1)\end{array}$} & 9 months & C. felis KM977642.1 & positive & - \\
\hline & & & & 11 months & C. spp. & negative & Toxocara cati \\
\hline
\end{tabular}

${ }^{*} \mathrm{Cl}-95 \%$ confidence interval according to the Wilson method.

**Accession No. of reference sequences deposited in GenBank (reference sequences chosen according to high similarity to obtained sequences). 


\section{Acknowledgments}

This research was supported by statutory research and development activity founds by Minister of Science and Higher Education assigned to Faculty of Veterinary Medicine, Wroclaw University of Environmental and Life Sciences, Poland.

\section{Conflict of interest}

The authors declare that they have no conflict of interest.

\section{REFERENCES}

1. Ryan U. Cryptosporidium in birds, fish and amphibians. Exp Parasitol. $2010 ; 124,113-120$.

2. Uehlinger, FD, Greenwood SJ, McClurea JT. Zoonotic potential of Giardia duodenalis and Cryptosporidium spp. and prevalence of intestinal parasites in young dogs from different populations on Prince Edward Island, Canada. Vet Parasitol. 2013; 196: 509-514.

3. Alves MEM, Martins FD, Bräunig P, Pivoto FL, Sangioni LA, Vogel, FSF. Molecular Detection of Cryptosporidium spp. and the occurrence of intestinal parasites in fecal samples of Naturally infected dogs and cats. Parasitol Res. 2018; 117: 3033-3038.

4. Yang R, Jie Ying J L, Monis P, Ryan U. Molecular characterisation of Cryptosporidium and Giardia in cats (Felis catus) in Western Australia. Exp Parasitol. 2015; 155: 13-18.

5. Li W, Li Y, Song M, et al. Prevalence and genetic characteristics of Cryptosporidium, Enterocytozoon bieneusi and Giardia duodenalis in cats and dogs in Heilongjiang province, China. Vet Parasitol. 2015; 208: $125-134$

6. Rosanowski SM, Banica M, Ellis E. The molecular characterization of Cryptosporidium species in relinquished dogs in Great Britain: a novel zoonotic risk? Parasitol Res. 2018; 117: 1663-1667.

7. Xu H, Jin Y, Wu W, et al. Genotypes of Cryptosporidium spp. Enterocytozoon bieneusi and Giardia duodenalis in dogs and cats in Shanghai, China. Parasit Vectors. 2016; 9: 121.

8. Paoletti B, Traversa D, Iorio R. Zoonotic parasites in feces and fur of stray and private dogs from Italy. Parasitol Res 2015; 114: 2135-2141.

9. Kostopoulou D, Claerebout E, Arvanitis D, Ligda P, Voutzourakis N, Casaert S, Sotiraki S. Abundance, zoonotic potential and risk factors of intestinal parasitism amongst dog and cat populations: The scenario of Crete, Greece. Parasit Vectors. 2017; 10: 43.

10. Hinney B, Ederer C, Stengl C, Wilding K, Štrkolcová G, Harl J, et al. Enteric protozoa of cats and their zoonotic potential-a field study from Austria. Parasitol Res. 2015; 114: 2003-2006.

11. de Lucio A, Bailo B, Aguilera M, Cardona GA, Fernández-Crespo JC, Carmena D. No molecular epidemiological evidence supporting household transmission of zoonotic Giardia duodenalis and
Cryptosporidium spp. from pet dogs and cats in the province of Álava, Northern Spain. Acta Trop. 2017; 170: 48-56.

12. Gundłach JL, Sadzikowski AB, Studzińska MB, Tomczuk K. Invasion of Giardia spp. and Cryptosporidium spp. in dogs and cats. Med Weter. 2004; 60 (11): 1202-1203.

13. Bajer A, Bednarska M. Cryptosporidium spp. and Giardia spp. infections in sled dogs. Med Weter. 2007; 63: 681-7.

14. Ryan U, Xiao L, Read C, Zhou L, Lal AA, Pavlasek I. Identification of Novel Cryptosporidium Genotypes from the Czech Republic. Appl Environ Microbiol. 2003; 69:7 4302-4307.

15. Cirak VY, Bauer C. Comparison of conventional coproscopical methods and commercial coproantigen ELISA kits for the detection of Giardia and Cryptosporidium infections in dogs and cats. Berl Munch Tierarztl Wochenschr. 2004; 117(9-10): 410-413.

16. Osman M, Bories J, El Safadi D, Poirel MT, Gantois N, BenamrouzVanneste, et al. Prevalence and genetic diversity of the intestinal parasites Blastocystis sp. and Cryptosporidium spp. in household dogs in France and evaluation of zoonotic transmission risk. Vet Parasitol. 2015; 214: 167-170.

17. Gil H, Cano L, de Lucio A, Bailo B, de Mingo MH, Cardona GA. Detection and molecular diversity of Giardia duodenalis and Cryptosporidium spp. in sheltered dogs and cats in Northern Spain. Infect Genet Evol. 2017; 50: 62-69.

18. Batchelor DJ, Tzannes S, Graham PA, Wastling J, Pinchbeck GL, German AJ. Detection of Endoparasites with Zoonotic Potential in Dogs with Gastrointestinal Disease in the UK. Transbound Emerg Dis. 2008; 55: 99-104.

19. Khan A, Shaik J, Grigg ME. Genomics and molecular epidemiology of Cryptosporidium species. Acta Trop. 2018; 184: 1-14.

20. Sannella AR, Suputtamongkol Y, Wongsawat E, Cacció SM. A retrospective molecular study of Cryptosporidium species and genotypes in HIV-infected patients from Thailand. Parasit Vectors. 2019; $12(1)$ : 91.

21. Sotiriadou I, Pantchev N, Gassmann D, Karanis P. Molecular identification of Giardia and Cryptosporidium from dogs and cats. Parasite. 2013; 20: 8 .

22. Ayinmode AB, Obebe OO, Falohun OO Molecular detection of Cryptosporidium species in street sampled dog faeces in Ibadan, Nigeria. Vet Parasitol Reg Stud Reports. 2018; 14: 54-58.

23. Kváč M, Hofmannová L, Ortega Y, Holubová N, Horčičková M, Kicia M. Stray cats are more frequently infected with zoonotic protists than pet cats. Folia Parasitol. 2017; 64: 034.

24. Šlapeta J. Cryptosporidiosis and Cryptosporidium species in animals and humans: a thirty colour rainbow? Int J Parasitol. 2013; 43: 957-970.

25. Aghamolaie S, Rostami A, Fallahi SH, Tahvildar Biderouni F, Haghighi A, Salehi N. Evaluation of modified Ziehl-Neelsen, direct fluorescentantibody and PCR assay for detection of Cryptosporidium spp. in children faecal specimens. J Parasit Dis. 2016; 40(3): 958-963.

26. Brar APS, Sood NK, Kaur P, Singla LD, Sandhu BS, Gupta K. Periurban outbreaks of bovine calf scours in Northern India caused by Cryptosporidium in association with other enteropathogens. Epidemiol Infect. 2017; 145: 2717-2726. 